\title{
Seasonal Adjustment of Some Financial Indicators of Pakistan
}

\author{
S. M. Husnain Bokhari \\ Joint Director, Statistics \& Data Warehouse Department, \\ State Bank of Pakistan. \\ Ishaque Ahmed Ansari * \\ Senior Joint Director, Statistics \& Data Warehouse Department, \\ State Bank of Pakistan.
}

\begin{abstract}
The paper describes the applied seasonal adjustment procedures used for analysis of the financial time series compiled by SBP. We have applied the X-12-ARIMA method in adjusting five important financial series: currency in circulation, broad money, remittances, exports and imports (from the balance of payments data). Adjusted series were found to be satisfactory, with in the tests and practices followed in X-12-ARIMA.
\end{abstract}

Keywords : Seasonal adjustment, X-12-ARIMA

\section{INTRODUCTION}

Economic and financial data series are often subject to seasonal variation. Seasonal fluctuations in data make it difficult to analyze whether the changes in data for a specified period reflect increases or decreases in the level of the data due to some underlying forces, or otherwise due to regularly occurring variation. Hence, the use of raw data in such cases can be quite misleading and necessitates the use of seasonally adjusted data. Also, in an economic analysis, the early assessment of overall business conditions, especially the identification of business cycle turning points, is possible only if the analysis is based on the most recent months of a time series. Critically, however, a reliable assessment of the overall trend depends on the series being free of seasonality and of effects attributable to calendar variations. If seasonality and calendar effects exist in a time series, information relevant for short-term economic analysis is obtained only after seasonal adjustment (which normally includes calendar adjustment as well).

Generally, seasonal adjustment is based on time series models which decompose an unadjusted series into the sum or the product of four unobservable components: trendcycle, seasonal, calendar and irregular. It is a process of estimating and removing seasonal effects from a time series. The seasonally adjusted data gives more readily interpretable measures of changes occurring in a specified period and reflects real economic movements without the misleading seasonal changes. Seasonally adjusted data is useful for financial institutions, government, policy makers, statisticians, econometricians and economists working in research institutions and universities.

* The material presented by the author does not necessarily portray the viewpoint of the editors and the management of the Institute of Business \& Technology (BIZTEK).

*Ishaque Ahmed Ansari : ishaque.ahmed@ sbp.org.pk

(c) JMSS is published by the Institute of Business and Technology (BIZTEK). Main Ibrahim Hydri Road, Korangi Creek, Karachi-75190, Pakistan. 
It has almost become a standard to use X-12-ARIMA approach for seasonal adjustment. Basically, X-12-ARIMA is a software package which combines regression analysis, time series modeling of univariate time series and a moving average approach for seasonal adjustment. Findley et al. (1998) give a very detailed description of the new improved capabilities of the X-12-ARIMA procedure. It includes RegARIMA program which handle regression and ARIMA models and a set of quality diagnostics. It has the capabilities for modeling and testing seasonality. This paper applies X-12-ARIMA methodology to estimate seasonal effects for time series of five financial variables compiled and disseminated by the State Bank. The five financial data series represent a number of challenges to seasonal adjustment and two of the series have raw data on stock basis, while the rest on monthly flow basis.

After introduction in Section-1, Section-2 describes the concept and presence of seasonality in the economic time series. Seasonal adjustment methodology behind the X-12-ARIMA procedure is discussed in Section-3. We briefly describe the choice between indirect and direct adjustment. Then we discussed the statistical tests and diagnostics. We also discussed the preadjustments of data series which are carried out prior to ARIMA modeling and seasonal adjustment. We also talked about the model selection criteria. A graphical examination of the five unadjusted time series is given in Section-4. The assessment of the final seasonal adjustment is explained in Section-5. The revision of seasonally adjusted data is discussed in Section-6. We concluded our paper in Section-7.

\section{SEASONALITY}

Seasonality means particular annual dependence. Many economic time series reveal seasonality. Seasonal effects can either be ascribed to the passing of seasons, e.g. harvesting or to more specific calendar effects resulting from Ramadan and Eid holidays, or specific days of the week. If seasonality is present in the time series data, it must be removed to give a clear picture of the data. The procedures of seasonal adjustment of financial time series do not vary from that of real economic time series. Financial time series are, however, to a higher degree than real economic time series affected by institutional changes.

Seasonal adjustment is a statistical technique for filtering out this systematic variation within the year, and thus simplifying the analysis of both the short-term and long- term development of the stock of currency in circulation.

Seasonally adjusted estimates are derived by estimating and removing the systematic calendar related variation from the original estimates. The seasonally adjusted estimates can be smoothed to obtain an estimate of the underlying direction, referred to as trend estimates. The irregular component is what is left after the trend and seasonal components are removed from the original estimates. Seasonally adjusted and trend estimates can be used to illustrate the short-term movements and the underlying level in social and economic time series. Of course, a seasonally adjusted series cannot be expected to be completely smooth. The seasonal adjustment method can only filter out the usual seasonal variations, i.e. those to be expected in the normal circumstances, from the movements of the time series. The effect of irregular influences, by contrast, is still present in the seasonally adjusted figures. The greater the significance of such influences is, the less smooth the seasonally adjusted series will be.

\section{SEASONAL ADJUSTMENT METHODOLOGY}

\subsection{The basic model used for seasonal adjustment}

Observed economic time series $Y_{t}$ can be decomposed into many unobserved seasonal and non-seasonal components that will provide useful and easily interpretable information. The model used for seasonal adjustment is quite simple. The basic principle is that an 
observed or actual time series is made up of three components as illustrated in Figure -1 of the Annexure:

- The long-term direction of the series removing all short-term fluctuations is referred to as the trend $\left(T_{t}\right)$, which not only includes the simple time trend, but also cyclical movements. The underlying upward movement in currency in circulation is an example of a trend. Trends can be upward, downward or cyclical. Detecting turning points in the trend is important for cyclical series.

- Short term fluctuations in the series which are assumed to occur annually including calendar effects (such as trading day effects, Ramadan effect etc.) called the seasonal component $\left(S_{t}\right)$. The increase in currency in circulation in the months of November and December is an example of a seasonal effect.

- The irregular component $\left(I_{t}\right)$, which contains all effects not explained by the trend or the seasonal component (including extreme observations such as outliers) but these can be due to a variety of reasons: abnormal weather, natural disasters, strikes and other unidentified reasons.

The decomposition can be either additive or multiplicative. Often financial and real macroeconomic time series are treated as multiplicative since the seasonal variation is dependent on the observed level. The decomposition can therefore be expressed as follows:

The multiplicative model:

$$
\operatorname{Actual}\left(Y_{t}\right)=\operatorname{Trendcycle}\left(T_{t}\right)+\operatorname{Seasonal}\left(S_{t}\right)+\operatorname{Irregular}\left(I_{t}\right) \quad t=1,2, \ldots \ldots, T
$$

and the additive model is:

$$
\operatorname{Actual}\left(Y_{t}\right)=\operatorname{Trendcycle}\left(T_{t}\right)+\operatorname{Seasonal}\left(S_{t}\right)+\operatorname{Irregular}\left(I_{t}\right) \quad t=1,2, \ldots \ldots, T
$$

Most adjusted series use a multiplicative decomposition however a multiplicative model cannot be implemented if there is zero or negative observed values in the series. It is assumed that the seasonal component is exogenous and that its movements are predictable. Under the multiplicative approach the seasonally adjusted figures are obtained by dividing the original series by the estimated seasonal component:

$$
\left(Y_{t} / S_{t}\right)=T_{t} \times l_{t} \quad t=1,2, \ldots . T
$$

In practice we can inspect the graph of the original data series to investigate the appropriate decomposition model. X-12-ARIMA provides a test to indicate whether the seasonality of a series is multiplicative or additive. Although the movements of the seasonal component are assumed to be predictable, they can change over time. In fact, it is quite likely that as time goes by, the seasonal pattern will change as a result of institutional changes. Hence the empirical analysis of the movements of the seasonal component becomes important, and should be monitored since it affects the choice of seasonal filters.

\subsection{X-12-ARIMA}

The X-11 software was the most widely used statistical method as developed by the US Census Bureau. The X-11 method has evolved as an experimental statistical method of seasonal adjustment implemented in early mainframe computers (Univac) (Shikin, Julius 1978). This program has further undergone numerous modifications and improvements, relating especially to the X-11-ARIMA software package. The X-12-ARIMA (Findley 1998), a first beta version has been made available since 1998. The X-11 method uses a set of moving averages to produce the seasonally adjusted data. The X-12-ARIMA is the 
most recent software package in the X-11 family (US Census Bureau 2006). It now merges the moving average technique with time series modeling. It has the advantage over X11 to use RegARIMA models (Regression models with ARIMA errors) for estimating calendar effects or outlier effects with predefined or user-defined regressors (Findley 1998). ARIMA modeling helps in identification of extreme values and of level shifts that could distort the seasonal adjustment. X-12-ARIMA has three predefined outlier types which user can specify as regression variables such as additive outliers (AO), level shift (LS) and temporary change (TC). The automatic outlier identification procedure of X-12ARIMA chose outliers by comparing regressor t-value to a critical value. The user can also set the t-value. It has wide-ranging statistical diagnostics, available graphically if desired, enabling the nature, robustness and stability of the seasonal adjustments to be easily monitored.

X-12-ARIMA procedure mainly consists of two stages: (i) a RegARIMA model is built for the time series under examination or its transformed values, e.g. log. Then the model is used to preadjust the series for several effects and for forecasting and backcasting. The RegARIMA time series regression error is the output of this stage; and (ii) this error is fed into X-12-ARIMA for seasonal adjustment. The adjusted series is decomposed into trend, seasonal and irregular components. The corresponding decomposition of the original series can be easily recovered by adding back the regressor effects and taking the inverse transformation if logs are modeled. Lastly, the adjusted series are inspected through X12-ARIMA diagnostics/quality assessment.

\subsubsection{The RegARIMA Models}

RegARIMA models are the widely used approach to preadjust the series for various effects and for forecasting and backcasting. These models are used to preadjust a series before seasonal adjustment by removing calendar effects such as trading-day, moving holidays and outliers. The series adjusted for such effects is extended for forecasts and backcasts with ARIMA models to avoid any loss of data while using moving average filters. The linear regression is applied for removing the day-of-the-week effect. A user-defined regressor is used in order to remove the effect of identified (un-identified) outliers in the current data series and thus to improve the forecast. The forecasts are used to calculate the seasonal component at the end of the series using symmetric filters and thus to improve the estimation of the seasonal component.

Initially, a model is estimated on the regressors and on the basis of this model, the automatic outlier selection is performed. The linear regression equation can be written as:

$$
\mathrm{y}_{t}=\sum_{i=1}^{k} \beta_{i} x_{i t}+\varepsilon_{t}
$$

Where $\mathrm{y}_{t}$ is the observed time series, $x_{i t}$ are regression variables (modeling the day-of theweek effect and the outliers), $\beta_{i}$ are regression parameters, $k$ is the number of regressors, $\varepsilon_{t}$ the residual from the regression model, $(t=1 \cdots n)$ and $(i=1 \cdots k)$. The regARIMA model then becomes of the following type:

$$
\phi_{p}(B) \mathrm{i}_{p}\left(B^{s}\right)(1-B)^{d}\left(1-B^{s}\right)^{D}\left[\mathrm{y}_{t}=3_{i=1}^{r} \beta_{i} x_{i t}\right] \theta_{q}(B) 0_{Q}\left(B^{s}\right) \varepsilon_{t}
$$

where $\varepsilon_{t}$ is white noise with mean 0 and variance $\sigma^{2}, \boldsymbol{B}$ is the backshift operator, where $\phi_{p}, \mathrm{i}_{p}, \theta_{q}$ and $0_{Q}$ are polynomials of order respectively and have all roots outside unit circle.

Moreover, the input series $\mathrm{y}_{t}$ is typically obtained from a nonlinear transformation of the original series (Findley 1998). It is sometimes useful to transform a series prior to estimating a RegARIMA model in order to stabilize the variance. More specifically, 


$$
y_{t}=f\left(\mathrm{Y}_{t}\right)=\left\{\begin{array}{l}
\mathrm{Y}_{t} \\
\log \left(\mathrm{Y}_{t}\right) \\
\lambda^{2}\left(\mathrm{Y}_{t}^{\lambda}-1\right) / \lambda, \quad \lambda=0
\end{array}\right.
$$

X-12-ARIMA produces two statistics that test the regARIMA model residuals for deviations from normality; both indicate kurtosis. One is Geary's statistics and Gastwirth and Owens statistics. A significant value of one of these statistics indicates that the standardized residuals do not follow a standard normal distribution. X-12-ARIMA tests for significance at one percent level. If the regARIMA model fits the data well, such lack of normality ordinarily causes no problem.

\subsubsection{The ARIMA Model}

It indicates the ARIMA part of the RegARIMA models. It describes a pure ARIMA model if the regression model is absent. While modelling financial time series, an appropriate assumption is that the residuals should be independently and identically distributed and uncorrelated over time. In fact, this is difficult to achieve and thus ARIMA modelling is used to model the estimated residuals from the linear regression in order to achieve uncorrelated error terms. The ARIMA part of the model may include multiplicative seasonal factors and operators with missing lags. The format follows standard Box-Jenkins (1976) notation. In this notation a nonseasonal ARIMA model is specifies as $(p, d, q)$, t where $\mathrm{p}$ is the nonseasonal AR order, $d$ is the number of nonseasonal differences, and $q$ is the nonseasonal MA order. A multiplicative seasonal ARIMA model is specified as $(p, d$, $q)(P, D, Q)$, where $\mathrm{p}, \mathrm{d}$, and $\mathrm{q}$ are as defined above, $\mathrm{P}$ is the seasonal AR order, $\mathrm{D}$ is the number of seasonal differences, and Q is the seasonal MA order. Here, the first ARIMA factor (p, d, q) is assumed to be nonseasonal (i.e. its period is one) and the second ARIMA factor $(\mathrm{P}, \mathrm{D}, \mathrm{Q})$ is assumed to be seasonal with the seasonal period set in the series spec. The general form of the ARIMA model can be written as:

$$
\phi_{p}(B) \mathrm{i}{ }_{p}\left(B^{s}\right)(1-B)^{d}\left(1-B^{s}\right)^{D} \mathrm{y}_{t}=\theta_{q}(B) 0{ }_{Q}\left(B^{s}\right) \varepsilon_{t}
$$

where is white noise with mean 0 and variance , B is the backshift operator, where are polynomials of order respectively and have all roots outside unit circle. The RegARIMA model is estimated by exact maximum by exact maximum likelihood (US Census Bureau 2006).

\subsubsection{The $X-11$ Procedure}

The actual seasonal adjustment is carried out using the outcome of the ARIMA modeling as input. This X-11 procedure is based on a moving average approach. The X-12-ARIMA uses an iterative approach to estimate the seasonal, trend and irregular components.

1. Initial estimates of trend are produced using a centered 12-term moving average. This estimate of trend is removed from the original series to produce an estimate of the combined seasonal/irregular component. Initial preliminary seasonal factors are produced by performing a $3 \times 3$ seasonal filter. The initial preliminary seasonal factors are then used to create more refined seasonal factors by estimating and removing the difference between the initial preliminary seasonal factor and a $3 \times 3$ moving average of the initial preliminary seasonal factor. This first iteration produces initial estimates of trend and seasonal factors.

2. Trend estimates are refined in the second iteration by using the initial seasonal factors in combination with a symmetric Henderson filter (Findley 1998). This refined trend is then used to create refined seasonal factors using essentially the; same process outlined in iteration 1. This second iteration produces final estimates of the seasonal 
component in the form of seasonal factors.

3. The third iteration uses the final seasonal factors produced in the second iteration combined with a Henderson filter to estimate a final trend component. Lastly, using final estimates of trend and seasonal components, an estimate of the irregular component is produced.

4. Outliers are identified from the estimates of irregular component and the actual value is replaced by an imputed value. A new trend cycle is obtained from the modified actual series. A seasonally adjusted series is then obtained by removing the seasonal factors from the modified actual series.

\subsection{Preadjustments}

Regression models in X-12-ARIMA are used to preadjust the series. The series are preadjusted for different breaks in the series, outliers, and for holidays. If the data is not preadjusted, the seasonal component will not be valid in the sense that it will be estimated on the basis of observations which represent more than the seasonal pattern in the series.

Financial time series data is sometimes affected due to unexpected interventions following an extraordinary observations or outliers. Outliers can badly bias the model identification, estimation and inference if these observations are not filtered out prior to modeling and seasonal adjustment. The quality of the final seasonal adjustment is strongly dependent on the outlier detection, because the seasonal filters are directly derived from the ARIMA model. There are three types of outliers found in practice in the preadjustment of the time series data: additive outliers (AO), transitory change (TC), and level shift (LS). The outlier detection and parameter estimation is performed by an automatic iterative procedure built into the X-12-ARIMA, where AO, TC and LS can be identified (Chang, Tiao \& Chen 2006). The procedure selects outliers by comparing regressor t-values to a critical value, which is either user-defined or the program's default value. Any outliers detected are included as regression variables.

Holidays effect can be examined through specific holidays such as official holidays occurring at fixed dated and moving holidays (Islamic holidays) occurring at changing intervals such as Ramadan, Eid-ul-Fitr, Eid-ul-Azha etc. Holiday effect is adjusted by forming a regression variable (regressors). If a month having any religious holidays, the regressor is the number of days of that holiday and zero otherwise. Separate regressors can be generated for the effect in intervals before and after holidays, as well as an intermediate effect around the holiday. More than one holiday can be specified, and the user can center these regressors using either their overall means or their calendar-month means (calendar-quarter means in the case of regressors for modeling quarterly data). X12-ARIMA commands can be output that allow the user to easily use these regressors in a regARIMA model for an X-12-ARIMA run. The moving holiday's effect is found to be significant at $5 \%$ level in the M2 series.

\subsection{Statistical tests and diagnostics}

X-12-ARIMA incorporates a set of statistical tests and diagnostics to evaluate the quality of the original series and the reliability of the seasonal adjustment. The seasonality in financial time series can be concluded both by visual inspection and by formal tests such as F-test for presence of seasonality and M-tests for presence of moving seasonality. The F-test, M-tests, M7 and SI ratios are used to assess the significance of seasonality in the series and how the seasonal filter should be incorporated. However, the quality of the seasonal adjustment can be assessed by test for presence of residual seasonality, $M$ statistics and their summary Q statistic and the spectrum to detect remaining seasonal or tradingday effects in the residual. Statistic M1 to M6 examines the magnitude and randomness 
of the final irregular component. Statistic M7 to M11 examines stable seasonality. Q statistics (weighted average of $M$ values) examines overall assessment on the quality of the seasonal adjustment. A smaller M / Q value indicates better quality of a seasonal adjustment. A smaller value of standard deviation indicates better quality of a seasonal adjustment. Values of M statistics from 1.0 to 1.2 may be accepted if other diagnostics indicate suitable adjustment quality.

\section{TIME SERIES PROPERTIES OF THE SELECTED FIVE FINANCIAL DATA SERIES FROM PAKISTAN}

In this section an inspection of the time series properties of broad money M2 is provided to explain the chosen transformations and preadjustments. As already mentioned, ARIMA modeling of financial time series is subject to strong assumptions about stationarity and normality of the residuals. Assume that $\mathrm{Y}_{t}$ is a realization of the stochastic process $\mathrm{y}_{t}$, then stationary process is a prerequisite in fitting a suitable model. This will become true when $\mathrm{y}_{t}$ has a constant variance $\left(\operatorname{Var}\left(\mathrm{y}_{t}\right)=\sigma^{2}\right)$ fluctuating around a constant mean $\left(E\left(\mathrm{y}_{t}\right)=\mu\right)$ and have uncorrelated errors $\left(\operatorname{Cov}\left(\mathrm{y}_{t-k,} \mathrm{y}_{t}\right)=0\right)$ for all $t$ 's.

Economic behavior in financial time series data is sometimes distinguished by nonstationary behavior and it is further emphasized while inspecting the time series graphs of M2 and Currency in Circulation (CIC) in the Chart 2.

Chart 2: Monetary Aggregates: Broad Money and Currency in Circulation in the Period 1995 to December 2007

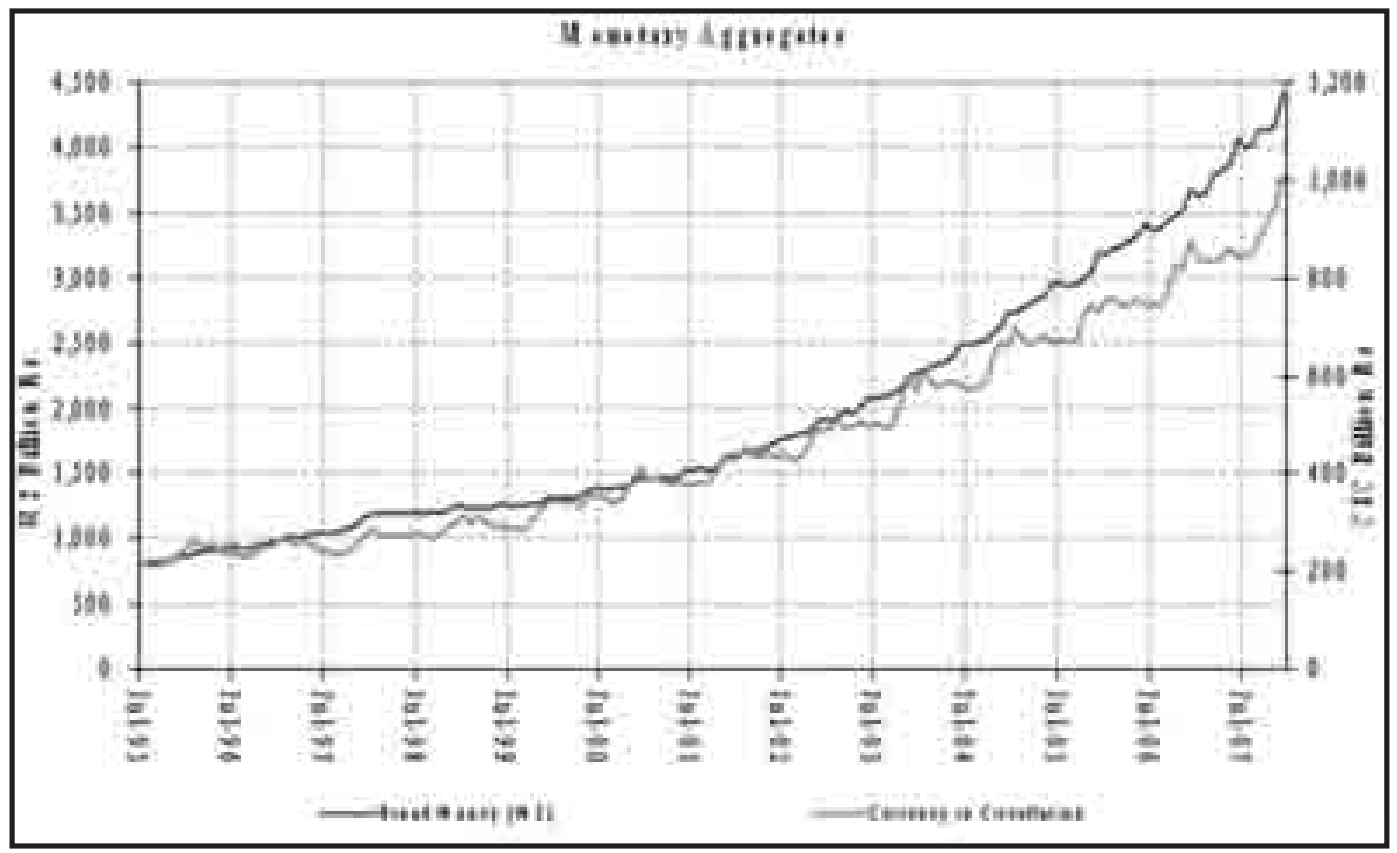

It is evident from Chart 2 that neither of the time series show any tendency to return to or fluctuate around a constant mean as time evolves. Both series (M2 and CIC) are clearly time-dependent and upward trending. This explains why transformation of the data is an important step towards meeting the requirements of stationary data, which, first of all, can 
be met by taking logarithms in order to reduce the time dependence of the variance. The graphs of Exports (BOP), Imports (BOP) and Worker's Remittance (WR) are given in Chart-5 and Chart 6 of the Annexure showing upward trending.

Since five data series showing upward trending, therefore, stationarity is not achieved by simple logarithmic transformation. By taking first differences, which are equal to having a series integrated of order $1(I(1))$, the series becomes stationary. This is shown below in chart 3 and chart 4 of the differenced series of M2, CIC, Exports (BOP) and Imports (BOP), where it is obvious from the growth of the transformed time series for the period from July 1995-December 2007 that there is a mean-reverting, smooth behavior.

Chart 3: Differenced Transformed series of Currency in Circulation and Broad Money Exports (BOP) and Imports (BOP)
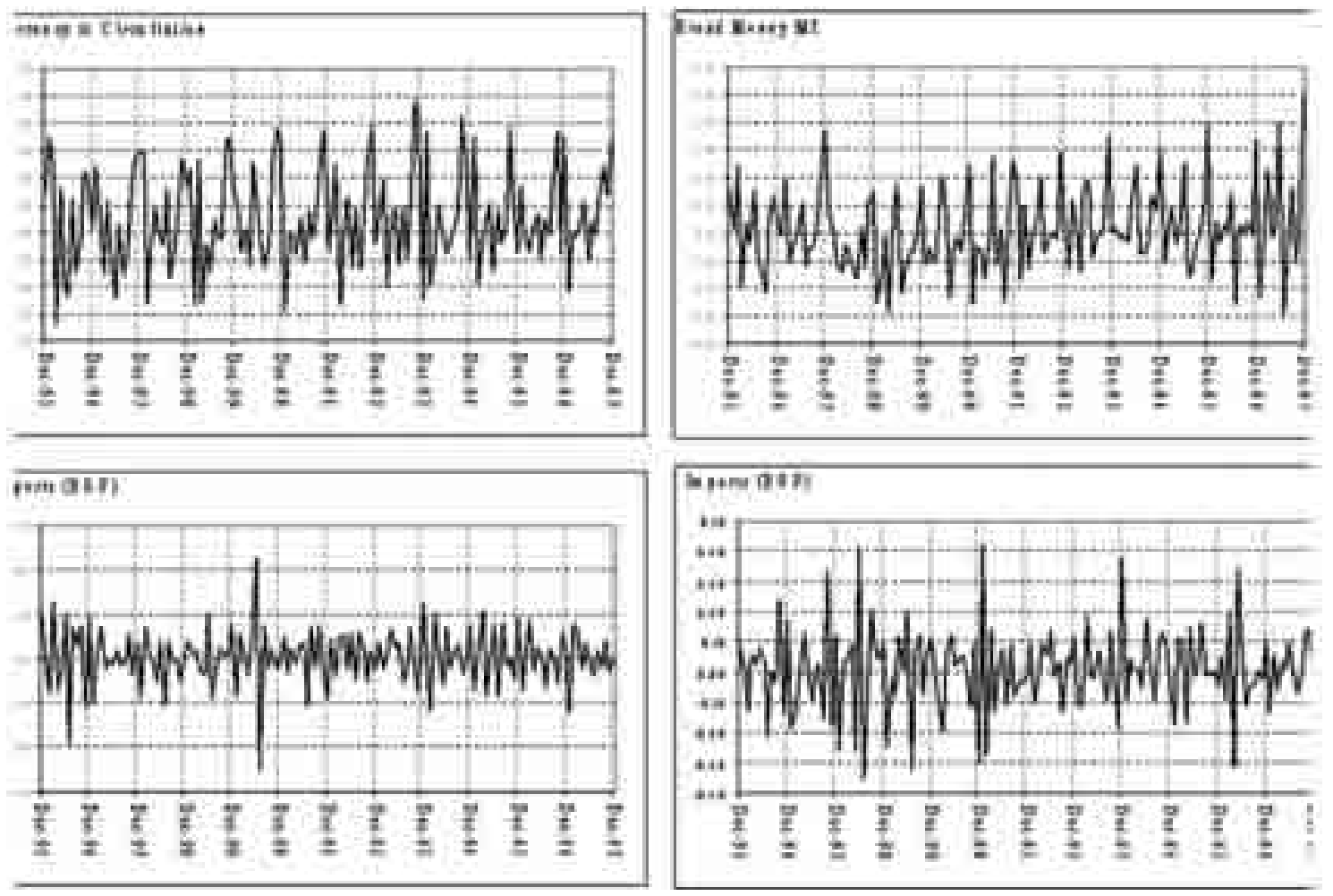

\section{SEASONAL ADJUSTMENT OF FINANCIAL DATA SERIES}

The seasonal adjustment of five data series of Broad Money (M2), Currency in Circulation (CIC), Workers' Remittances (WR), Exports (BOP) and Imports (BOP) is based on Census X-12-ARIMA, Version 0.2.10. All data series are unadjusted monthly series. All have a time span of length more than ten years (from July 1995 to December 2007).

The above-mentioned test statistics confirm the seasonal adjustment of the data series. In Table- 1 of the Annexure some of the various test statistics are presented and by inspection it becomes clear that none of the estimated models suffer from serious autocorrelation or lack of normality. Broad money having moving seasonality as defined by the $F_{M}$ statistics, but none of the data series violate the assumption of identifiable seasonality. It means the 
seasonal adjustment of the data series is manageable.

As an example, in Chart-4 of the Annexure, the Seasonal-irregular (SI-ratios) of February and September for currency in circulation are shown. The SI-ratios for both months are quite steady and there is a little difference between using a $3 \times 3,3 \times 5$, or $3 \times 9$ filter. A $3 \times 5$ filter is chosen. There is no sign of residual seasonality in either of the seasonally adjusted series. There are no problems with M1-M11 and Q statistics (see Annexure). Generally, the seasonal adjustment of all the data series investigated seems stable as can be seen from the Chart-7 of Annexure for original and seasonally adjusted series of all the data series; showing seasonally adjusted series are smoother than the original series.

\section{REVISIONS}

When using seasonally adjusted data, revisions of the unadjusted data are important. The inclusion of new information affects the adjustment of the time series as a result of X-12ARIMA using centered moving averages to forecast observations for trends and the seasonal component. When new data is added, forecasts will be replaced by actual observations, which can cause deviations and thus revisions of data is important.

Generally, when new data become available, revisions are important in order to make improvement of the seasonally adjusted series. The revision can be made either in each month when new data become available (i.e. concurrent adjustment) (Pierce, David \& Mckenzie 1987) or seasonal factors projected at predetermined longer intervals such as semi-annual/annual (i.e. factor projected adjustment). The use of concurrent adjustment is preferable since new data always reveal new information and thus should be used. But the problem with this adjustment is that the recent data is not as reliable as historical data, It is more computationally intense because re-estimation of seasonal component should be undertaken as each new observation become available and therefore it is also important consideration when deciding on revision policy. Therefore, factor projected adjustment is preferred.

The general practice is to avoid from frequent revisions and to provide seasonally adjusted data based on projected seasonal factors, particularly whenever the seasonal components seem stable. Table- 1 of the Annexure shows that the expected forecast error of the five adjusted series is small; the smallest is for the currency in circulation, $1.48 \%$, and the largest is for the workers' remittances, $10.59 \%$.

All financial seasonally adjusted series are constructed based on forecasted seasonal factors i.e. X-12 ARIMA program will run after availability of bi-annual data such as each August and February, program will be executed independently and each time appropriate X-12ARIMA model is chosen for each of the data series. On the basis of the selected model, the seasonal factors will be re-estimated for the complete time range and forecasted for the following six months. This means that all the seasonally adjusted data series will be revised on the basis of new seasonally adjusted factors due to revision of the selected data series and inclusion of new data. In the following six months, seasonal adjustment is based on the forecasted factors. For seasonal adjustments during the year, forecast seasonal factors are used and seasonal factors are reestimated twice a year. In addition, seasonal factors can be reviewed in the case of large data revisions.

\section{CONCLUSION}

This paper has illustrated that a seasonal adjustment procedure can be set up in more than one way. Accordingly, seasonally adjusted data cannot have the same official status as unadjusted data, and it is important that the chosen method for seasonal adjustment is explained and documented properly. It is also clear that the specific application of the X12-ARIMA package may change as experience accumulates. 
We have applied the X-12-ARIMA method in adjusting five important financial series compiled by SBP: currency in circulation, broad money, remittances, exports and imports (from the balance of payments data). Adjusted series were found to be satisfactory, with in the tests and practices followed in X-12-ARIMA.

\section{REFERENCES}

Bell, W. R. and S. C. Hillmer (1984), "Issues involved with the seasonal adjustment of economic time series", Journal of Business and Economic Statistics, 2 (4), pp. 98-127.

Bobbitt, L. and M. Otto (1990), "Effects of forecasts on the revisions of concurrent seasonally adjusted data using the X-11 seasonal adjustment procedure", U.S. Bureau of the Census.

Burman, J. P. and M. C. Otto (1988), "Outliers in time series", Bureau of the census, Statistical division report series.

Burnett, Mhairi (2006), "Seasonal adjustment of UK monetary aggregates: direct versus indirect approach", Retrieved from http://www.bankofengland.co.uk/statistics/ms/articles/art1feb06.pdf

Chang, I., G. C. Tiao, and C. Chen (1988), "Estimation of Time Series Parameters in the Presence of Outliers", Technometrics, 30 (2), pp. 193-204.

Chen, C. and L.-M. Liu (1993), "Joint estimation of model parameters and outlier effects in time series", Journal of the American Statistical Association, 88(421), pp. 284-297.

Chiu K, Higginson J, and Huot G. (1985), "Performance of ARIMA models in Time Series", Survey Methodology, II, pp.51-64.

Cleveland, W. S. and Devlin, S. J. (1980), "Calendar Effects in Monthly Time Series: detection by Spectrum Analysis and Graphical Methods", Journal of American Statistical association, Vol. 75, pp. 487-496.

Deutsche Bundesbank (1999), "The changeover from the seasonal adjustment method Census X-11 to Census X-12-ARIMA", Monthly Report, Deutsche Bundesbank, 51(9), September.

European Central Bank (2000), "Seasonal adjustment of monetary aggregates and HICP for the euro area", August 2000.

Findley, D. F., B. C. Monsell, H. B. Shulman and M. G. Pugh (1990), "Sliding spans diagnostics for seasonal and related adjustments", Journal of the American Statistical Association 75, pp. 345-355.

Findley, D. F., B. C. Monsell, W. R. Bell, M. C. Otto, and B.-C. Chen (1998), "New Capabilities and Methods of the X-12-ARIMA Seasonal Adjustment Program", Journal of Business and Economic Statistics, 16 (2), pp. 127-176.

Ghysels, E. and D. R. Osborn (2001), "The Econometric Analysis of Seasonal Time series", Cambridge University Press, Cambridge.

Gourieroux, C. and Monfort, A. (1997), Time Series and Dynamic Models", Cambridge University Press.

Granger, Clive, W. J. (1979), "Seasonality: Causation, Interpretation, and Implications", Chapter in NBER book Seasonal Analysis of Economic Time Series. pp 33 - 56. Retrieved from http://www.nber.org/chapters/c3896

Hood, C. C., and Findley, D. F. (2001), "Comparing Direct And Indirect Seasonal Adjustments of Aggregate Series", Retrieved from www.census.gov/ts/papers/choodasa2001.pdf

Jahan, Sayeeda B., Talukder, Serajul Islam (2003), "Seasonal Adjustments of Time Series and Its importance in Bangladesh Bank", Journal of Institute of Bankers, Bangladesh, Vo. 50, No. 2, pp. 155-182.

Kathleen M. McDonald-Johnson and Catherine C. Hood (2001), "Outlier Selection for RegARIMA Models", Retrieved from www.census.gov/ts/papers/asa2001kmm.pdf

Ladiray, D. and Quenneville, B. (1999), "Understanding the X11 Method: The Various Tables", Working paper series, Time series research and analysis centre, Statistics Canada. 
Lothian, J. and Morry, M. (1978), "A Set of Quality Control Statistics for the X-11-ARIMA Seasonal Adjustment Method", Retrieved from www.census.gov/ts/papers/LothianMorry1978.pdf

Manna, M. and R. Peronaci (2003), "Seasonal Adjustment. European Central Bank, January 2003.

McDonald-Johnson, K. M., and C. C. Hood (2001). Outlier selection for RegARIMA Models. U.S. Census Bureau. Retrieved from www.census.gov/pub/ts/papers/asa2001kmm.pdf

Murdoch, K., V. Wilcox, G. Kuzmicich, and F. Krsinich (2000), "The effect of forecasting on revisions to seasonally adjusted time series", Working paper series, Statistics New Zealand.

Pierce, D. A. and S. K. McKenzie (1985), "On concurrent seasonal adjustment", Bureau of the Census, statistical research division report series, July 1985, no. CENSUS/SRD/RD$85 / 09$.

Pierce, David and Sandra McKenzie (1987), "On Concurrent Adjustment," Journal of the American Statistical Association 82, 720-732.

Riazuddin, R. and Khan, M. H. (2002), "Detection and Forecasting of Islamic Calendar Effects in Time Series data", State Bank of Pakistan Working Papers.

Shiskin, Julius (1978), "Keynote Address: Seasonal Adjustment of Sensitive Indicators", In A. Zellner, Editor, Seasonal Analysis of Economic Time Series, pp. 97-103, US Census Bureau. Retrieved from www.nber.org/chapters/c3898.pdf

Soukup, R. J. and Findley, D. f. (1999), "On the spectrum Diagnostics Used by X-12 ARIMA to Indicate the Presence of Trading day Effects After Modeling or Adjustment", Proceedings of the American Statistical Association, Business and Economic Statistics Section, Alexandria, pp.144-149.

U.S. Census Bureau, Time Series Staff (2006), "X-12-ARIMA Reference Manual", Version 0.3, U.S. Census Bureau. Retrieved from http://www.census.gov/srd/www/x12a/

ANNEXURE

Figure-1

Time Series Components

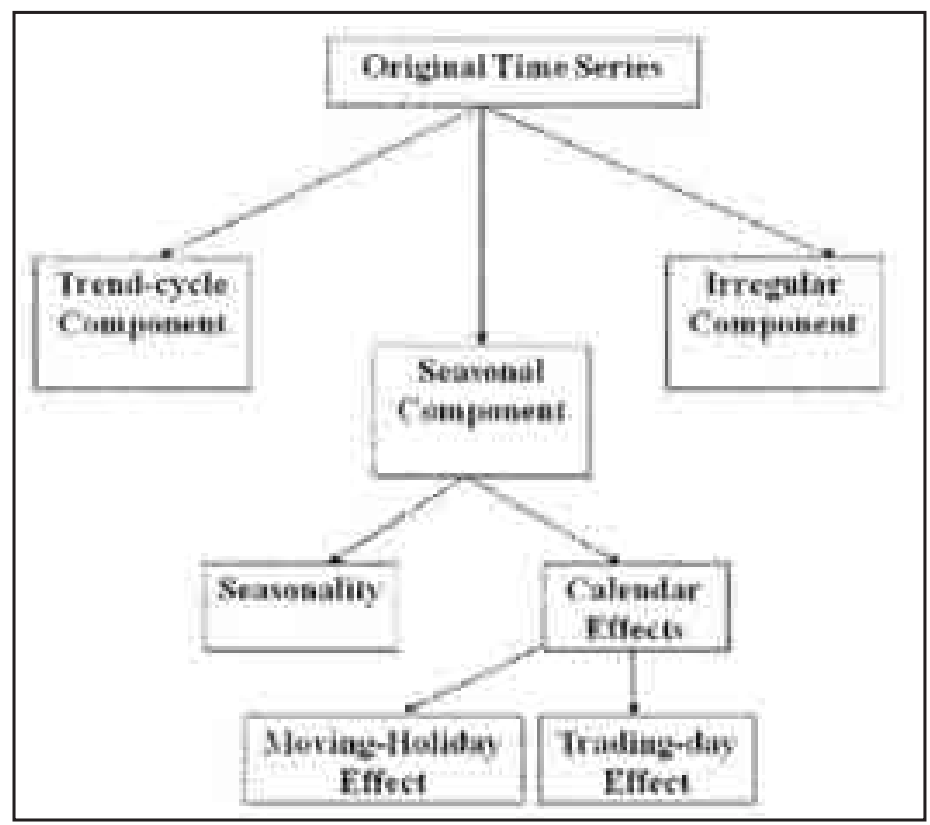


Chart 4

Modified Seasonal-Irregular Components (SI-Ratios) \& Filters Calculated for Currency in Circulation for September and February
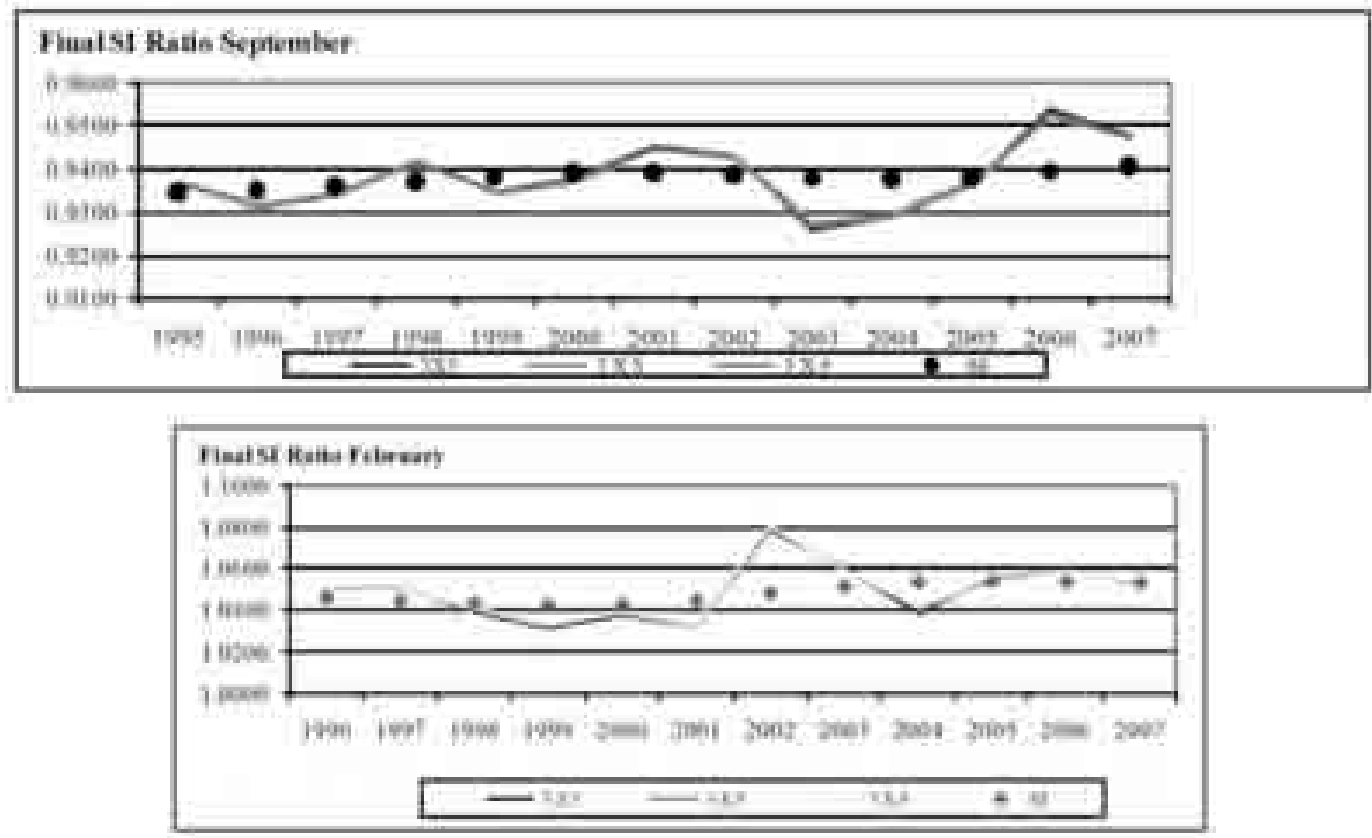

Chart 5

Exports (BOP), Imports (BOP) in the period July 1995 - December 2007

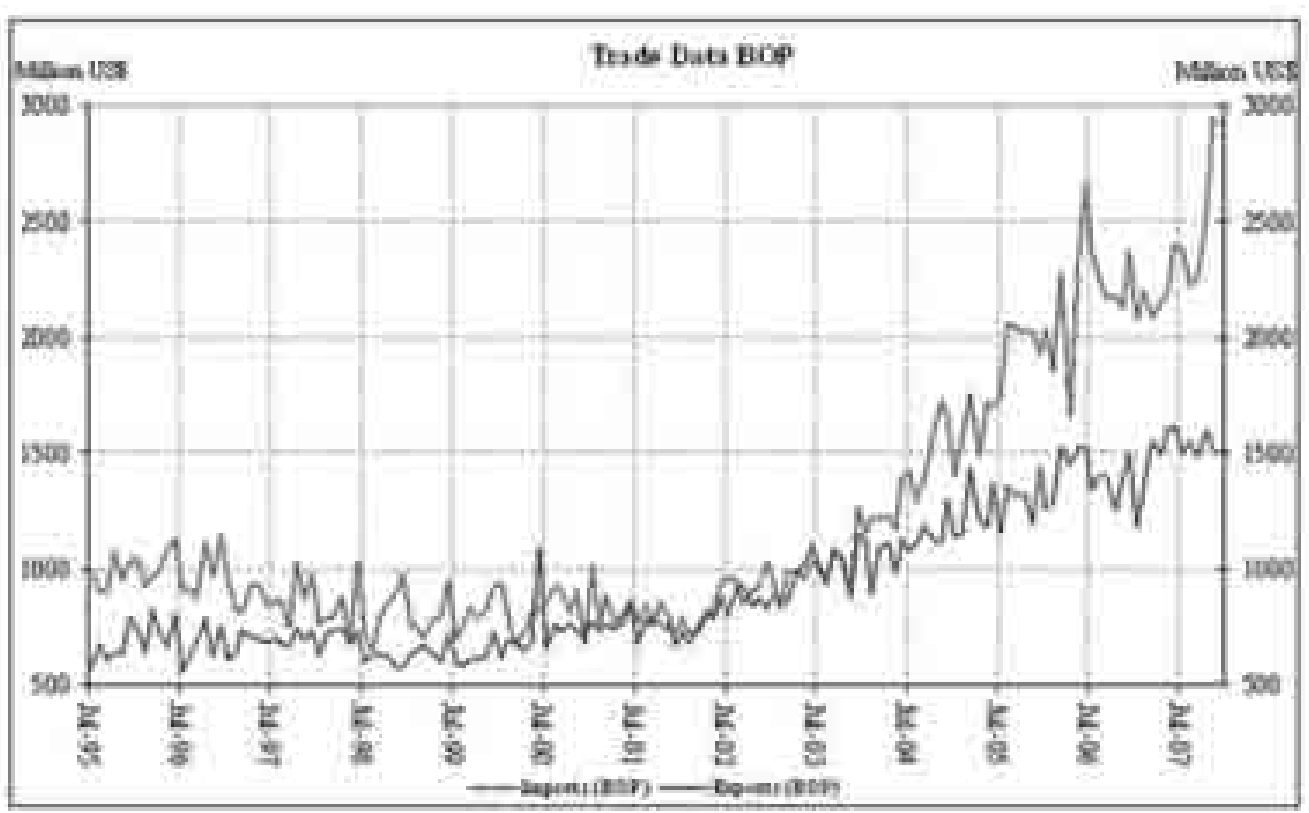


Chart 6

Workers' Remittances in the period July 1995 - December 2007

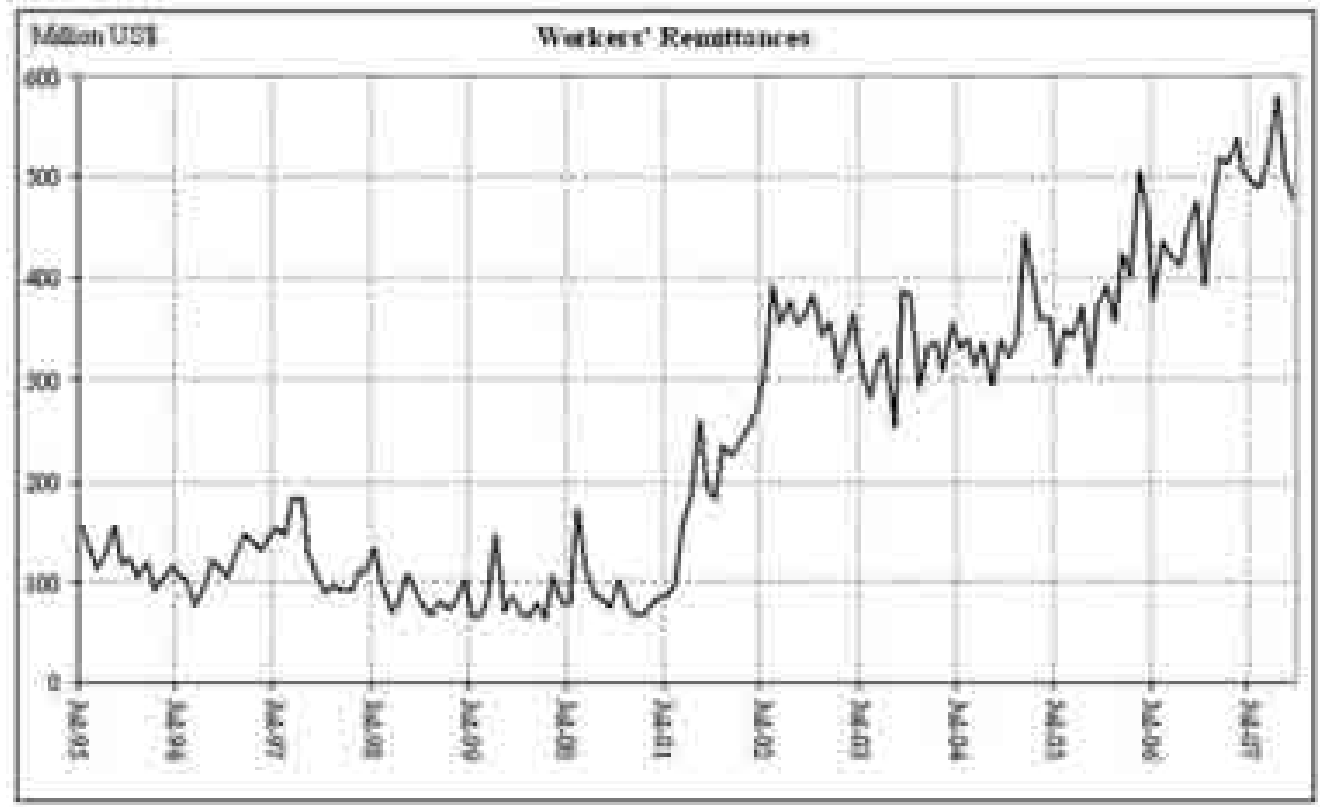

Chart 7

Original versus Seasonally Adjusted Data Series

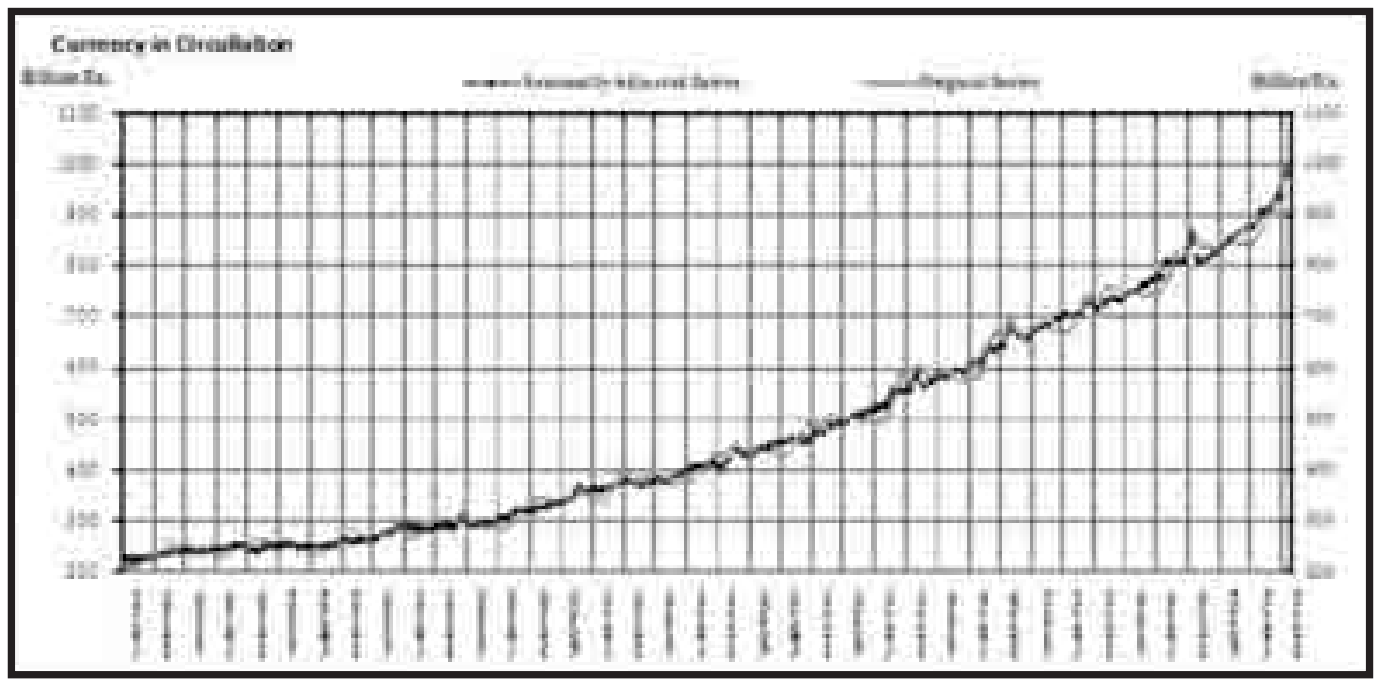



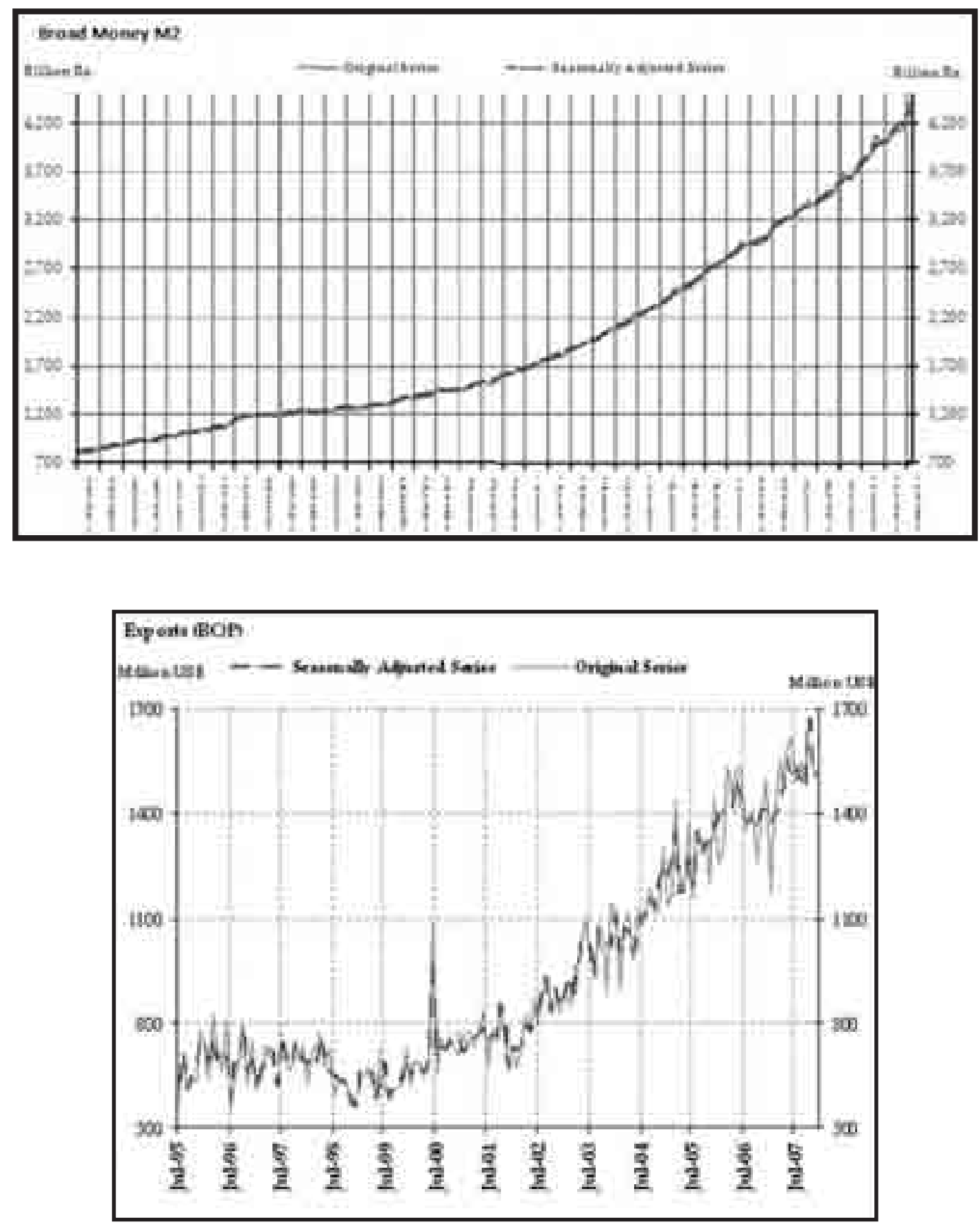

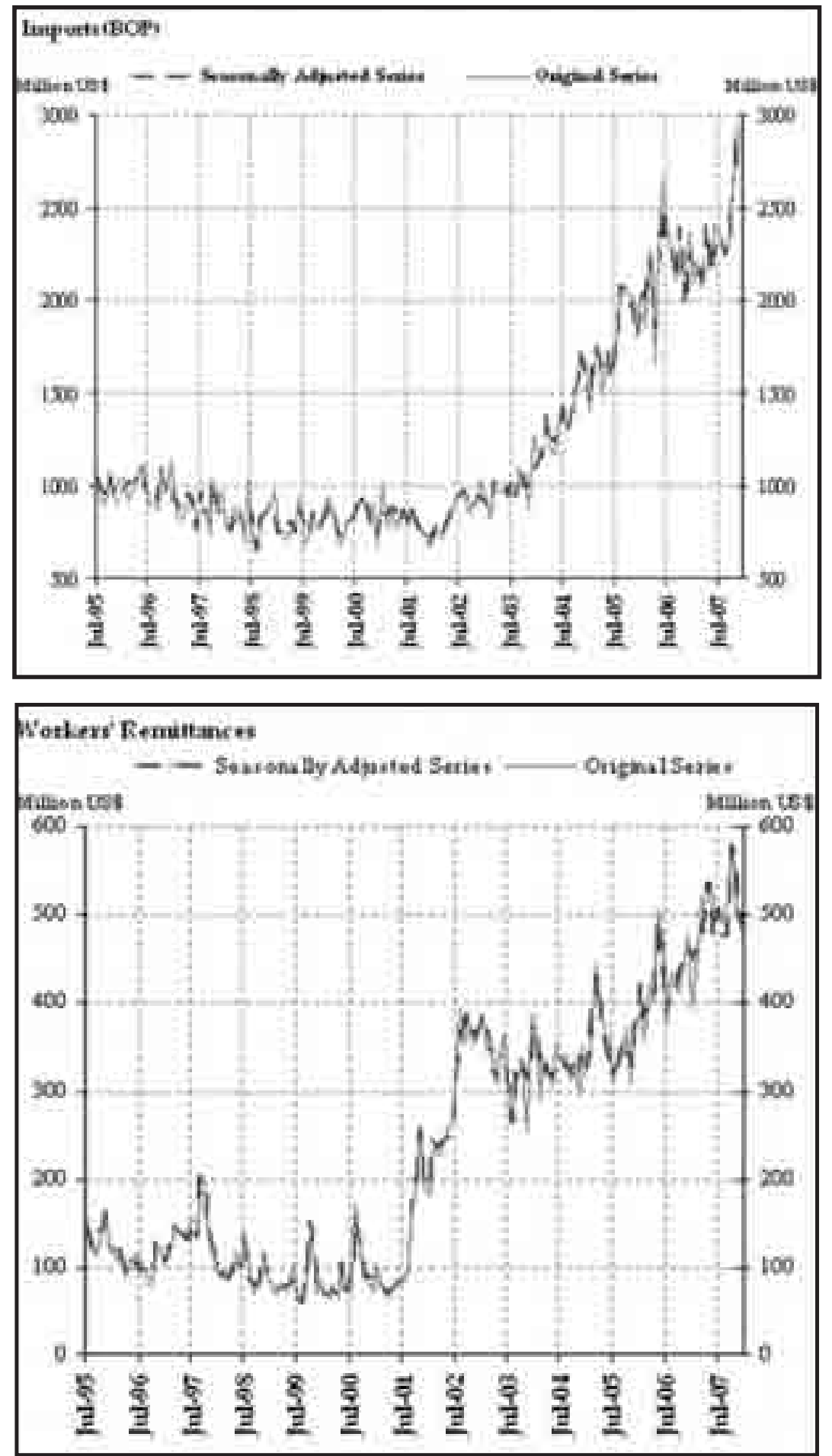
Table-1

Seasonal Adjustment Results for the Five Monthly Financial Data Series

\begin{tabular}{|c|c|c|c|c|c|}
\hline Statistics & $\begin{array}{c}\text { Currency in } \\
\text { Circulation } \\
\text { (CIC) }\end{array}$ & $\begin{array}{l}\text { Broad Money } \\
\text { (M2) }\end{array}$ & $\begin{array}{c}\text { Workers' } \\
\text { Remittances } \\
\text { (WR) }\end{array}$ & $\begin{array}{l}\text { Export } \\
\text { (BOP) }\end{array}$ & $\begin{array}{l}\text { Import } \\
\text { (BOP) }\end{array}$ \\
\hline Model & $\left.\begin{array}{|llllllll} & 3 & 1 & 1\end{array}\right)\left(\begin{array}{lllll}0 & 1 & 1\end{array}\right)$ & $\left(\begin{array}{lllllll}0 & 1 & 1\end{array}\right)\left(\begin{array}{llll}0 & 1 & 1\end{array}\right)$ & $\left.\begin{array}{|lllllll}(2 & 1 & 0\end{array}\right)\left(\begin{array}{lllll}0 & 1 & 1\end{array}\right)$ & $\left.\begin{array}{|llllll}(0 & 1 & 1\end{array}\right)\left(\begin{array}{llll}0 & 1 & 1\end{array}\right)$ & 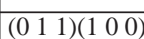 \\
\hline No of Estimated Parameters & 20 & 16 & 26 & 23 & 18 \\
\hline No of Observations & 150 & 150 & 150 & 150 & 150 \\
\hline \multicolumn{6}{|l|}{ RegARIMA Related } \\
\hline Adjusted loglikelihood & -1408 & -1526 & -625.377 & -741.959 & -905.001 \\
\hline AIC & 2856 & 3084 & 1302.754 & 1529.918 & 1846.002 \\
\hline Hannan-Quinn & 2880 & 3103 & 1333.606 & 1557.209 & 1867.970 \\
\hline BIC & 2915 & 3131 & 1378.674 & 1597.077 & 1900.073 \\
\hline \multicolumn{6}{|l|}{ Residual Normality \& Autocorrelations } \\
\hline Kurtosis & 3.43 & 3.25 & 3.3850 & 2.5715 & 2.6874 \\
\hline \multicolumn{6}{|l|}{ Forecasting Performance } \\
\hline $\begin{array}{l}\text { Average absolute percentage error in out-of-sample } \\
\text { forecasts (last } 3 \text { years) }\end{array}$ & 1.48 & 1.57 & 10.59 & 4.13 & 8.90 \\
\hline \multicolumn{6}{|l|}{ Preliminary \& Evaluating tests } \\
\hline FS Test & 117.53 & 46.01 & 9.942 & 16.910 & 7.098 \\
\hline Presence of stable seasonality & Yes & Yes & Yes & Yes & Yes \\
\hline FM Test & 0.37 & 2.40 & 1.18 & 0.849 & 1.584 \\
\hline Presence of moving seasonality & No & Yes & No & No & No \\
\hline FS test (residual seasonality) & 0.53 & 0.05 & 0.60 & 0.19 & 0.24 \\
\hline Presence of residual seasonality & No & No & No & No & No \\
\hline M1 & 0.095 & 0.039 & 0.807 & 0.888 & 1.273 \\
\hline M2 & 0.092 & 0.012 & 0.097 & 0.344 & 0.214 \\
\hline M3 & 0.000 & 0.000 & 0.364 & 0.660 & 1.014 \\
\hline M4 & 0.735 & 0.129 & 0.101 & 0.932 & 0.857 \\
\hline M5 & 0.108 & 0.000 & 0.329 & 0.472 & 0.387 \\
\hline M6 & 0.227 & 0.580 & 0.059 & 0.187 & 0.331 \\
\hline M7 & 0.19 & 0.39 & 0.73 & 0.53 & 0.91 \\
\hline M8 & 0.39 & 0.87 & 0.73 & 0.67 & 0.85 \\
\hline M9 & 0.31 & 0.51 & 0.71 & 0.37 & 0.74 \\
\hline M10 & 0.35 & 0.98 & 0.90 & 0.83 & 0.89 \\
\hline M11 & 0.34 & 0.95 & 0.90 & 0.76 & 0.89 \\
\hline \multicolumn{6}{|l|}{ Outliers Identified } \\
\hline \multirow[t]{10}{*}{$\mathrm{AO}$} & 99.Mar & 01.Aug & 98.Jul & 96.Jul & 98.Aug \\
\hline & $(7.25)$ & $(2.87)$ & $(4.58)$ & $(-3.24)$ & $(-2.89)$ \\
\hline & 01.Dec & 07.Feb & 98.Nov & 96. Oct & \\
\hline & $(-3.80)$ & $(3.23)$ & $(3.41)$ & $(2.97)$ & \\
\hline & 06.Dec & & 99.Sep & 98.Dec & \\
\hline & $(5.05)$ & & (3.37) & $(-2.39)$ & \\
\hline & & & 99.Oct & 00.Jun & \\
\hline & & & $(7.57)$ & $(6.48)$ & \\
\hline & & & 00.May & & \\
\hline & & & $(4.79)$ & & \\
\hline \multirow[t]{4}{*}{ TC } & 00.Jun & & 97.Sep & 95.Dec & \\
\hline & $(4.33)$ & & $(4.64)$ & $(2.54)$ & \\
\hline & & & 2000.Aug & 01.Dec & \\
\hline & & & $(7.22)$ & $(-3.98)$ & \\
\hline \multirow[t]{2}{*}{ LS } & & & 01.Sep & & \\
\hline & & & $(7.24)$ & & \\
\hline \multicolumn{6}{|l|}{ Regressors } \\
\hline Ramadan & $-0.4 \%$ & $0.2 \%$ & $0.7 \%$ & $1.9 \%$ & $4.5 \%$ \\
\hline Dul-Haj & $3.1 \%$ & $0.6 \%$ & $13.8 \%$ & $0.6 \%$ & $5.5 \%$ \\
\hline $\begin{array}{l}\text { Standard deviation of month-to-month \% change } \\
\text { in the seasonally adjusted series }\end{array}$ & 2.16 & 1.36 & 19.91 & 8.60 & 10.11 \\
\hline Series & Stock & Stock & Flows & Flows & Flows \\
\hline Data Source & Weekly & Weekly & Monthly & Monthly & Monthly \\
\hline
\end{tabular}


Figure 2

Seasonal Factors of the Financial Data Series
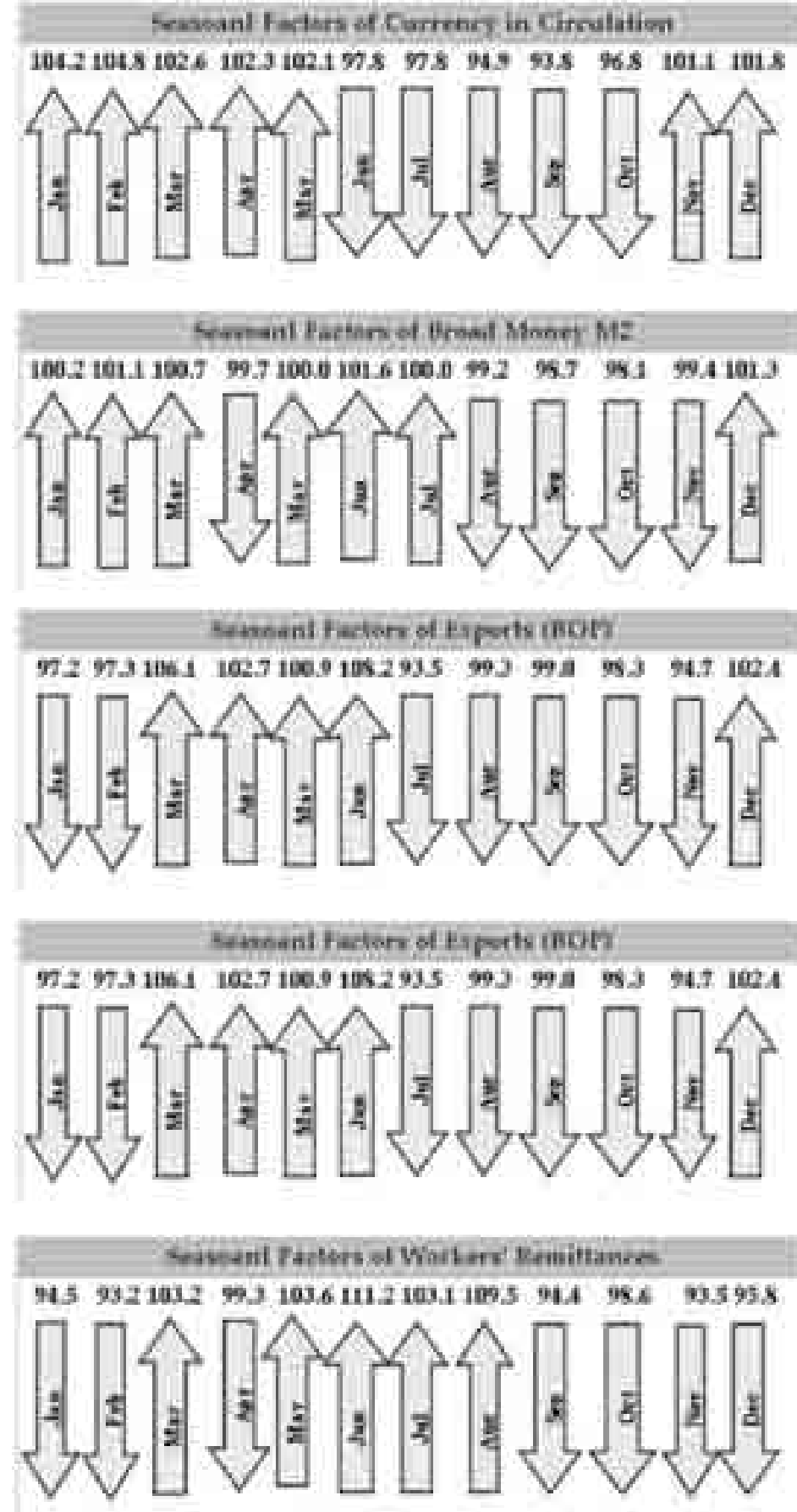